\title{
Caracterização do catalisador e da casca de ovo in natura pelo método do indicador de Hammett
}

\author{
Castro, L. S. ${ }^{1 *}$; Barañano, A. G. ${ }^{2}$ \\ 1 Discente do Programa de Pós-Graduação em Engenharia Química, Universidade Federal do Espírito Santo, Alegre, \\ ES, Brasil. \\ 2 Docente do Programa de Pós-Graduação em Engenharia Química, Universidade Federal do Espírito Santo, Alegre,
} ES, Brasil.

* e-mail: lucienecasttro@hotmail.com

\section{Resumo}

O catalisador $\mathrm{CaO}$ foi obtido a partir da calcinação da casca de ovo in natura é um resíduo orgânico abundante no mundo. A basicidade qualitativa e quantitativa do catalisador e da casca de ovo in natura foram determinadas através do método de Hammett, um método simples e rápido. O catalisador apresentou uma força básica 9,8 $\leq \mathrm{H}_{-}<12,2$ enquanto a casca de ovo in natura apresentou $\mathrm{H}_{-} \leq 3,5$. A casca de ovo de in natura não pode ser utilizada como catalisador devido não possuir sítios ativos, porém a casca de ovo calcinada foi promissora como catalisador heterogêneo.

Palavra - chave: casca de ovo, método de Hammett, catalisador.

\begin{abstract}
The $\mathrm{CaO}$ catalyst was obtained from calcination in nature eggshell is an abundant organic waste in the world. The qualitative and quantitative basicity of the catalysts and eggshell in nature and were determined through the Hammett method, a simple and fast method. The catalysts showed a basic strength $9.8 \leq \mathrm{H}_{-}$ $<12.2$ while the eggshell in nature showed $H_{-} \leq 3.5$. The eggshell in nature cannot be used as catalysts because it don't have actives sites, but the calcined eggshell was promising as heterogeneous catalyst.
\end{abstract}

Keywords: eggshell, Hammett method, catalyst.

\section{Introdução}

A casca de ovo é constituída basicamente por carbonato de cálcio, é um subproduto da indústria de processamento de ovos pouco valorizado, no entanto apresenta um potencial econômico [1].
De acordo com [2] estimam-se 240 mil ton. de casca de ovo foram geradas em 2015, sendo estas geralmente são descartadas em aterro sanitário sem nenhum tratamento [3]. A disposição adequada deste resíduo é muito importante, pois pode evitar poluição ambiental e risco para a saúde pública [4], no entanto, implica alto custo para a indústria [5]. Deste modo, o uso deste 
material como catalisador minimiza a disposição em aterro, bem como o impacto sobre as reservas naturais de rocha calcária, uma fonte natural de carbonato de cálcio não-renovável [6]. Além disso, é um catalisador de baixo custo e abundante que pode diminuir custo final do processo.

Recentemente os pesquisadores iniciaram os estudos da casca de ovos como catalisador para a produção de biodiesel em diferentes matérias primas e verificaram que este catalisador é promissor para a essa finalidade. [7] e [8] utilizaram o óleo de soja e obtiveram um rendimento de ésteres de $95 \%$ e $90 \%$ respectivamente. Em seguida, [9] investigaram o óleo de karanja e alcançaram um rendimento de ésteres de $97,43 \%$. [10] testaram o óleo de oleína de palma e obtiveram um rendimento de ésteres de 94,1\%. [11] e [12] avaliaram óleo de palma e alcançaram um rendimento de ésteres de $96,7 \%$ e $94 \%$ respectivamente. [13] testaram o óleo de girassol e obtiveram um rendimento de ésteres de $97,75 \%$. [14] utilizaram o óleo de canola e o rendimento de ésteres alcançado foi de 96\%. [15], [16] e [17] utilizaram como matéria prima, o óleo de fritura e alcançaram um rendimento de ésteres de $100 \%$, de $95,05 \%$ e de $94 \%$, respectivamente. O sebo bovino foi utilizado por [18] e obtiveram um rendimento de ésteres de $82,43 \%$, enquanto [19] usaram o óleo de pinhão manso e obtiveram um rendimento de ésteres de $90 \%$.

O catalisador $\mathrm{CaO}$ é caracterizado pela identificação dos minerais e a cristalografia, pela composição química dos elementos presentes, pela estabilidade térmica e perda de massa (resultantes da decomposição dos carbonatos em óxidos), pela identificação dos grupos funcionais, pelas informações a respeito da morfologia (textura, tamanho e forma das partículas), pelo volume dos poros, diâmetro médio dos poros, pela área específica, pela basicidade através do tipo de força e quantidade de sítios básicos [20].

Dentre essas caracterizações do catalisador destaca-se a determinação da basicidade ou acidez através método indicador Hammett, é uma técnica simples e de baixo custo. [21], [22] e [23] utilizaram o método do indicador Hammett para determinação da basicidade dos catalisadores.
Neste trabalho foi abordada a preparação e a análise da basicidade do catalisador $\mathrm{CaO}$ obtido a partir da casca de ovo.

\section{Materiais e métodos}

\subsection{Matéria-prima}

Foram coletadas $500 \mathrm{~g}$ de cascas de ovo nas residências localizadas no município de Sooretama - ES no período de 01 de março a 01 de abril de 2016.

\subsection{Preparação do catalisador}

As cascas de ovo foram lavadas com água destilada. Após a lavagem, as cascas de ovos foram secas em estufa à $105^{\circ} \mathrm{C}$, durante $24 \mathrm{~h}$ [24]. Em seguida, as cascas foram trituradas com o auxílio de almofariz e pistilo até a obtenção de um pó fino. A amostra triturada foi peneirada a seco e classificado na faixa de 16 a 35 mesh. A amostra foi calcinada em forno de alta temperatura à $1000^{\circ} \mathrm{C}$ durante $1 \mathrm{~h}$ à uma taxa de aquecimento de $2,5^{\circ} \mathrm{C} / \mathrm{min}(\mathrm{C} 1)$.

\subsection{Força básica do catalisador}

A força de basicidade é a capacidade da superfície do sítio converter em um ácido neutro, em outro ácido neutro adsorvido na sua forma de base conjugada. Essa força é expressa pela função de basicidade de Hammett, assumindo que a mudança de cor observada dos indicadores adsorvidos corresponde à conversão de $50 \%$ de moléculas neutras em base [25].

A força de basicidade $\left(\mathrm{H}_{\_}\right)$da casca de ovo in natura e do catalisador foi determinada através de metodologia adaptada de [26].

\subsection{Sítios Básicos}

A determinação quantitativa foi através de titulação utilizando ácido benzóico. Essa análise fornece o número de sítios básicos presentes no catalisador.

A determinação dos sítios básicos da casca de ovo in natura e do catalisador foi feita através de metodologia adaptada de [26].

$$
H_{-}=p K_{B H}
$$




\section{Resultados e Discussões}

\subsection{Preparação do catalisador}

A casca de ovo in natura é rica em carbonato cálcio, porém esse composto é pouco ativo, portanto é necessário realizar um tratamento térmico, a calcinação, para obtenção da fase ativa do catalisador, o óxido de cálcio.

A casca de ovo in natura apresentou uma coloração ligeiramente amarelada, Figura 1a, e após a calcinação foi nítida a mudança de coloração para branca Figura 1b, cor característica do óxido de cálcio, confirmando a presença desse composto [27].

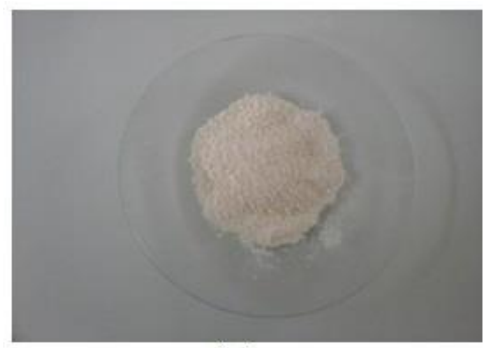

(a)

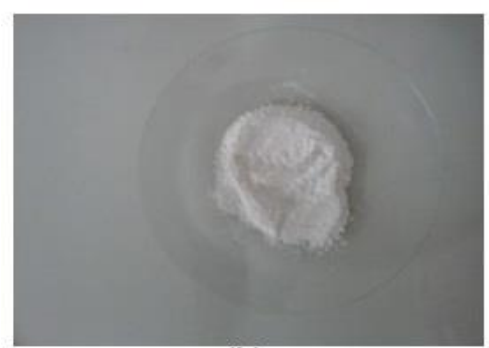

(b)

Figura 1 : (a) Casca de ovo in natura; (b) Casca de ovo calcinada C1.

\subsection{Força básica do catalisador}

Esta é uma análise qualitativa da basicidade da casca de ovo in natura e do catalisador, onde é possível verificar a força básica pela observação na mudança de cor dos indicadores.

A figura 2 ilustra as soluções padrões dos indicadores e a basicidade da casca de ovo in natura e do catalisador. A casca de ovo in natura não houve mudança de cor em nenhum dos indicadores utilizados, isso indica que não possui força básica elevada conforme observa-se na figura 2.2a, 2.3a, 2.4a, 2.5a e 2.6a.

O catalisador (C1) não alterou apenas no indicador alaranjado de metila 2.2b, acredita-se que devido ao baixo valor de $\mathrm{pK} \mathrm{BH}_{\mathrm{BH}}$ não foram perceptíveis as mudanças de cor. O catalisador apresentou ligeiramente uma cor verde claro no indicador índigo de carmim 2.6b, logo mostra uma pequena transição na coloração das amostras em relação à solução padrão que apresenta cor azul, no entanto não atinge a coloração do meio básico deste indicador, a cor amarela. A mudança de cor nos indicadores indica que o catalisador apresenta força básica.

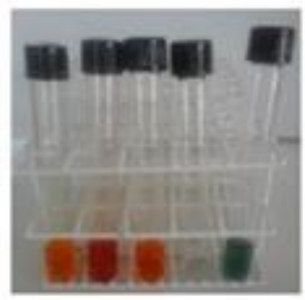

(1)

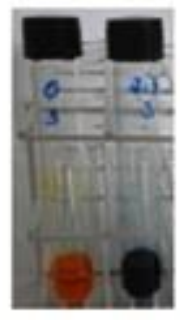

(a) (b)

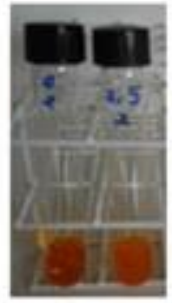

(a) (b)

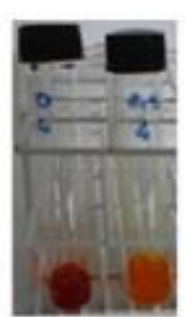

(a) (b)

\section{(2)}

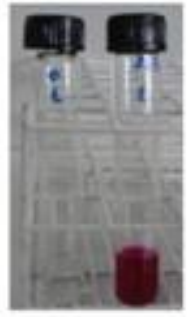

(a) (b)
(3)

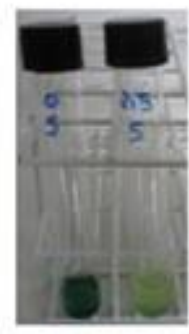

(a) (b)
(4)

(5)

(6)

Figura 2: (1) Indicadores usados na análise qualitativa de basicidade na ordem: alaranjado de metila, vermelho de metila, azul bromotimol, fenolftaleína e índigo carmim; (2) - (a) basicidade da casca de ovo in natura utilizando alaranjado de metila; (b) basicidade do catalisador utilizando alaranjado de metila; (3) -(a) basicidade da casca de ovo in natura utilizando vermelho de metila; (b) basicidade do catalisador utilizando vermelho de metila; (4) - (a) basicidade da casca de ovo in natura utilizando azul de bromotimol, (b) basicidade do catalisador utilizando azul de bromotimol; (5) - (a) basicidade da casca de ovo in natura utilizando fenolftaleína; (b) basicidade do catalisador utilizando fenolftaleína; (6) - (a) basicidade utilizando de índigo de carmim de casca de ovo in natura, (b) basicidade utilizando de índigo de carmim do catalisador.

\subsection{Sítios Básicos}

A casca de ovo in natura não apresentou basicidade, isso significa que não apresenta sítios ativos com força muito elevada e enquanto o catalisador $\mathrm{C} 1$ apresentou basicidade no indicador com $\mathrm{pK}_{\mathrm{BH}}=5$ até $\mathrm{pK}_{\mathrm{BH}}=9,8$, sendo que no $\mathrm{pK} \mathrm{K}_{\mathrm{BH}}=5$ apresentou maior quantidade de sítios ativos, conforme se observa na tabela 1 . 
Tabela 1: Quantidade de sítios básicos totais: casca de ovo in natura e C1.

\begin{tabular}{|c|c|c|c|c|c|c|}
\hline \multirow[t]{2}{*}{ Amostra } & & \multicolumn{5}{|c|}{ Basicidade $\left(\mathrm{mmol} \mathrm{g}^{-1}\right)$} \\
\hline & $\mathrm{pK}_{\mathrm{BH}}=3,5$ & $\mathrm{pK}_{\mathrm{BH}}=5$ & $\mathrm{pK}_{\mathrm{BH}}=7,1$ & $\mathrm{pK}_{\mathrm{BH}}=9,8$ & $\mathrm{pK}_{\mathrm{BH}}=12,2$ & Total \\
\hline $\begin{array}{c}\text { Casca de ovo in } \\
\text { natura }\end{array}$ & - & - & - & - & - & 0 \\
\hline C1 & - & 0,969 & 0,459 & 0,337 & - & 1,766 \\
\hline
\end{tabular}

\section{Conclusão}

Concluímos que a casca de ovo calcinada tem potencial para ser utilizada como catalisador, em virtude de ser um catalisador básico e apresentar sítios ativos. A casca de ovo calcinada apresentou elevada força básica $9,8 \leq \mathrm{H}_{-}$ $<12,2$ e enquanto a casca de ovo in natura apresentou $\mathrm{H}_{-}<3,5$.

\section{Agradecimentos}

Os autores agradecem a FAPES pelo apoio financeiro e ao IFES e a UFES pela infraestrutura para o desenvolvimento dos experimentos.

\section{Referências}

[1] Oliveira, D. A., Benelli, P.; Amante, E. R. Valorização de resíduos sólidos: casca de ovos como matéria-prima no desenvolvimento de novos produtos. In: International Workshop Advances in Cleaner Production, 2, 2009, São Paulo. Anais. Disponível em:< http://www.advancesincleanerproduction.net/second/file s/sessoes/6a/1/E.\%20R.\%20Amante\%20-

\%20Resumo\%20Exp\%20-\%206A-1.pdf>.

[2] ABPA - ASSOCIAÇÃO BRASILEIRA DE PROTEÍNA ANIMAL. ABPA Mídia, 2016. Disponível em: <http://abpa-br.com.br/noticia/producao-de-ovos-dobrasil-cresce-61-e-chega-a-395-bilhoes-de-unidades1550>. Acesso em: 05 de Fevereiro de 2016.

[3] TSAI, W.T. et al. Biores. Technol. v. 99, p. 16231629, 2008.

[4] WITOON, T. Cer. Int., v. 37, p. 3291-3298, 2011.

[5] GUEDES, F. H. Reaproveitamento de resíduo de casca de ovo e chamote na produção de material cerâmico para isolação térmica. 170 f. Dissertação (Mestrado Engenharia e Ciências dos Materiais),
Programa de Pós-Graduação em Engenharia e Ciências dos Materiais, Universidade Estadual Norte Fluminense, Campos dos Goytacazes, 2014.

[6] OLIVEIRA, D. A.; BENELLI, P.; AMANTE, E. R. J. Clean. Prod, v. 46, p. 42-47, 2013.

[7] WEI, Z.; XU, C.; LI, B. Biores.Technol., v. 100. p. 2883-2885, 2009.

[8] MAJHI, S.; RAY, S. Environ. Sci. and Pollut. Res., v. 23, p. 9251-9259.

[9] SHARMA, Y. C.; SINGH, B.; KORSTAD, J. Fuel, v. 90, p. 1309-1324, 2011.

[10] VIRIYA-EMPIKUL, N. et al. Biores. Technol., v.101, p. 3765-3767, 2010.

[11] KHEMTHONG, P. et al. Cat. Today, v. 190, p. 112116, 2012.

[12] BUASRI, A. et al. Sust. Energ., v.1, p. 7-13, 2013.

[13] CORREIA, L. M. et al. Biores. Technol., v.151, p. 207-213, 2014.

[14] JAZIE, A. A.; PRAMANIK, H.; SINHA, A. S. K. IJSDGE, v.2, p. 2315-4721, 2013.

[15] NAVAJAS, A. et al. Asia-Pac. J. Chem. Eng., v. 8, p. $742-748,2013$.

[16] NIJU, S.; BEGUM, K. M. M. S.; ANANTHARAMAN, A. N. Environ. Prog. \& Sustain. Energy, v.34, p. 248 254, 2014.

[17] TAN, Y. H. et al. Appl. Energy, v.160, p.58 - 70, 2015.

[18] CUACA, V.; WENDI; TASLIM. Effect of Reaction Time and Molar Ratio of Alcohol to Beef Tallow for Producing Biodiesel from Waste Beef Tallow Using Heterogeneous Catalyst $\mathrm{CaO}$ from Waste Eggshell. In: 
Proceedings of Sriwijaya International Seminar on Energy and Environmental Science \& Technology, 5, 2014, Palembang. Anais eletrônicos...Disponível em: $<$ http://ejournal.unsri.ac.id/index.php/siseest/article/view /1622 >. Acesso: 20 de Dez. de 2015.

[19] CHAVAN, S. B. et al. R. S. C., v. 5, p.63596-63604, 2015.

[20] CORREIA, L. M. Caracterização e aplicação de catalisadores heterogêneos obtidos a partir de fontes naturais à base de óxidos básicos para produção de biodiesel. 140 f. Dissertação (Mestrado em Engenharia Química) - Programa de Pós-Graduação em Engenharia Química, Universidade Federal do Ceará, Fortaleza, 2012.

[21] KOUZU, M.; HIDAKA, J.S. Fuel, v. 93, p. 1-12, 2012.

[22] BOEY, P. L.; MANIAM, G. P.; HAMID, S. A. J. Oleo Sci., v. 58 p. 499-502, 2009.

[23] BIRLA, A. et al. Biores. Technol., v. 106, p. 95-100, 2012.

[24] CHAKRABORTY, R.; BEPARI, S.; BANERJEE, A. Chem. Eng. J., v. 165, p. 798-805, 2010.

[25] KIJENSKI, J.; ZIELINSKI, B.; ZADROZNY, R., J. Res. Inst. Catalysis, Hokkaido Univ. v. 27, p. 145 158, 1979.

[26] SILVA, L. C. A. D. Argilas modificadas para uso como catalisadores heterogêneos em reações de transesterificação: efeito da composição química das argilas. 101 f. Dissertação (Mestrado em Engenharia Química) Programa de Pós-Graduação em Engenharia Química, Universidade Estadual do Oeste do Paraná, Toledo, 2013.

[27] PEREIRA, J. G. et al. Termogravimetria: um novo enfoque para a clássica determinação de cálcio em cascas de ovos. Quim. Nova, v. 32, p. 1661-1666, 2009. 